\title{
ALÉM DA ACESSIBILIDADE: DESAFIOS DA SOCIALIZAÇÃO ORGANIZACIONAL DE PESSOAS COM DEFICIÊNCIA EM UMA INSTITUIÇÃO FEDERAL DE ENSINO SUPERIOR
}

\author{
BEYOND ACCESSIBILITY: CHALLENGES FOR ORGANIZATIONAL \\ SOCIALIZATION RELATED TO PEOPLE WITH DISABILITIES IN A FEDERAL \\ INSTITUTION OF HIGHER EDUCATION
}

\author{
Maria do Socorro Martins dos Santos \\ Universidade Federal do Ceará - UFC \\ socorromartins.ufc@gmail.com \\ Tereza Cristina Batista de Lima \\ Universidade Federal do Ceará - UFC \\ tcblima@uol.com.br \\ Serafim Firmo de Souza Ferraz \\ Universidade Federal do Ceará - UFC \\ sfsf@uol.com.br
}

Submissão: 26/04/2019

Aprovação: 12/12/2019

\begin{abstract}
RESUMO
Analisa as percepções das pessoas com deficiência sobre a socialização organizacional em uma Instituição Federal de Ensino Superior. A amostra foi composta por 15 servidores com deficiência, selecionados pela condição de deficiência e, por conveniência, de acordo com a disponibilidade dos profissionais em participar do estudo. $\mathrm{O}$ ensaio caracteriza-se como demanda qualitativa, na qual foi realizado um estudo de caso, tomando-se como referencial o modelo teórico adaptado de Chao et al. (1994), Taormina (1997) e Borges et al. (2010), que culminou nas dimensões - engajamento à instituição, integração às pessoas, domínio profissional e perspectivas futuras. Para a coleta de dados, utilizou-se um roteiro de entrevista semiestruturada e, no tratamento dos dados, foi realizada a análise de conteúdo com auxílio do software Atlas Ti, versão 8.0. Os resultados apontam que houve um crescimento no número de pessoas com deficiência dentro da instituição, mostrando aquelas que estão ingressando como detentoras de uma qualificação elevada e que pretendem continuar se aperfeiçoando, mas, também, mostraram que existem muitas dificuldades relacionadas à acessibilidade nas suas mais distintas modalidades.
\end{abstract}

Palavras-chave: Socialização. Pessoas com Deficiência. Instituição Federal de Ensino Superior. 


\section{ABSTRACT}

This article evaluates perceptions expressed by people with disabilities in relation to organizational socialization in a Federal Institution of Higher Education. The sample consisted of 15 public servants with disabilities, selected by their disability condition and, for convenience, according to their availability as professionals to participate in the study. The essay is characterized as a qualitative demand, in which a case study was chosen, taking as reference the adapted theoretical model of Chao et al. (1994), Taormina (1997) and Borges et al. (2010), which culminated in the dimensions - engagement with the institution, integration with people, professional mastery and futures perspectives. For data collection, a semistructured interview script was used, and a content analysis was performed with the aid of the Atlas Ti software, version 8.0. Results indicate that there has been a growth in the number of people with disabilities within the institution, showing those who are entering as holders of a high qualification and aiming at continuing improvement, but also showed that there are many difficulties related to accessibility in their most different modalities.

Keywords: Socialization. Disabled people. Federal Institution of Higher Education.

\section{INTRODUÇÃO}

Pessoas com deficiência foram, no decorrer da história, vítimas de preconceito e segregação social. Na Grécia Antiga, a deficiência era vista como um obstáculo para a sobrevivência e subsistência do povo (SANTOS et al., 2016). Muitos anos se passaram e as pessoas com deficiência passaram também por diversas fases até chegarem a ter maiores oportunidades de inclusão na sociedade e nos ambientes organizacionais.

Moreira, Cappelle e Carvalho-Freitas (2015) ressaltam que o comportamento da pessoa perante o diverso retrata não só o comportamento que a organização espera dela, mas também sua visão de mundo. Esta cosmovisão, a pouco e pouco, se modifica. Por tal razão, Moreira, Cappelle e Carvalho-Freitas (2015) ressaltam, no artigo "A dinâmica identitária de pessoas com deficiência: um estudo no Brasil e nos Estados Unidos", que muitas organizações destacam a importância da diversidade e criam ações que incentivam essa prática. E muitas organizações, mesmo existindo legislação que obriga a contratação de pessoas com deficiência, procuram incluir parâmetros de responsabilidade social como fator diferencial e que reúne valor à empresa.

Desde a Lei $\mathrm{n}^{\circ}$ 8.213/91- Lei das Cotas (regulamentada pelo Decreto 3.298/99), o Governo atribuiu às empresas parte da responsabilidade de incluir pessoas com deficiência na sociedade (PHILERENO et al., 2015).

De igual maneira, como a Lei das Cotas ampliou o número de trabalhadores com deficiência nas empresas privadas, no âmbito das Instituições Federais de Ensino Superior (IFES), a Lei 8.112, de 11 de dezembro de 1990, reserva 20\% dos lugares em concurso para pessoas com deficiência, o que resultou também no aumento de vagas desses profissionais com deficiência, que passaram por decursos de socialização para integração aos quadros de servidores dessas instituições.

Os institutos públicos enfrentam desafios para atrair, desenvolver e reter seus profissionais. Neste âmbito, destaca-se a importância da socialização organizacional, pois esta possibilita que a pessoa se familiarize com a cultura da instituição, compreenda os valores e adquira conhecimentos e habilidades para que ela assuma os papéis a si designados (GENARI; IBRAHIM; IBRAHIM, 2017).

Com amparo nessa visão, a pesquisa foi norteada pela seguinte indagação central: Como pessoas com deficiência percebem seus processos de socialização organizacional em 
uma Instituição Federal de Ensino Superior?

Para responder à pergunta, a pesquisa tem como objetivo geral analisar as percepções de pessoas com deficiência acerca da socialização organizacional em uma Instituição Federal de Ensino Superior, tomando como referência quatro dimensões: engajamento à instituição, integração às pessoas, domínio profissional e perspectivas futuras.

\section{A SOCIALIZAÇÃO NO CONTEXTO ORGANIZACIONAL}

O termo socialização significa o ato de impor a estrutura de ação de uma sociedade a uma pessoa ou grupo. Ela possui gradações, pois o ser humano pode ser mais ou menos socializado (LEVY JR, 1980). "Uma pessoa encontra-se adequadamente socializada (grifo do autor) se lhe foram inculcados elementos das estruturas de ação da sociedade, de modo a se lhe possibilitar o desempenho eficaz dos seus papéis". (LEVY JR, 1980, p. 60).

Ao debaterem a sociedade como formulação social da realidade, Berger e Luckmann (2013) esclarecem que a socialização ocorrente no mundo do trabalho pode ser considerada um modo de socialização secundário. Constitui a chamada "socialização organizacional", que, para Borges e Albuquerque (2014), pode ser aquela destinada a promover a integração das pessoas aos cargos, para que sejam efetivadas como membros organizacionais.

Os estudos sobre socialização tiveram início nos anos de 1960, consoante Schein (1988), motivados, entre outros fatores, pela necessidade de profissionalização da gestão de pessoas nas organizações, pela mobilidade de trabalhadores entre empresas, filiais e postos de trabalho e em razão da necessidade de entender melhor aspectos facilitadores e entraves do ato de se inserir funcionários em novos contextos.

Borges et al (2014) e Borges e Albuquerque (2014) perceberam a evolução dos estudos sobre socialização com amparo em quatro enfoques: o das táticas organizacionais, o de cunho desenvolvimentista, o dos conteúdos e da informação e o das tendências integradoras.

No enfoque das táticas organizacionais, Borges et al. (2010) acentuam que a atenção se direciona nas ações da organização que visam a facilitar a socialização. Busca-se descobrir as dimensões segundo as quais as táticas se diferenciam ou podem ser classificadas, bem como a que objetivos cada tipo de tática pode servir.

Van Maanen (2007) oferece sete estratégias de socialização empregadas na organização: formais e informais; individuais e coletivas; sequenciais e não sequenciais; fixas e variáveis; por competição ou por concurso; em série e isoladas; e estratégias de socialização por meio de investidura e despojamento. Essas estratégias são empregadas pelas organizações para controlar e dirigir o comportamento de seus membros.

No enfoque desenvolvimentista, na percepção de Borges et al. (2010), o foco mudou de atenção das ações organizacionais para os processos cognitivos que os componentes da socialização organizacional vivenciam. No enfoque dos conteúdos e da informação, de acordo com Oliveira et al. (2008), as pesquisas consideram a proatividade, entendendo que os novatos em uma empresa são agentes ativos que buscam as pessoas e os locais de aprendizado para facilitar a própria adaptação, sendo capazes de influenciar as normas do grupo e os resultados de desempenho.

O modelo de socialização proposto por Chao et al. (1994) ocorre no âmbito do enfoque dos conteúdos e da informação. Os autores realizaram uma pesquisa com 1.038 participantes de uma universidade pública dos Estados Unidos e uma faculdade (college). Agruparam, então, diversos conteúdos da socialização do ponto de vista de seus pesquisados em uma escala com seis fatores (BORGES et al., 2010): proficiência de desempenho, pessoas, políticas, história, linguagem e objetivos e valores organizacionais.

No Brasil a corrente dos conteúdos e da informação é a predominante nos estudos 
sobre socialização organizacional, sendo o estudo de Chao et al. (1994) o que mais influenciou os pesquisadores nacionais (ANDRADE et al., 2012). Já as tendências integradoras, como a própria denominação explica, segundo Andrade et al. (2012), integram as anteriores de maneira tal a complementá-las, porquanto estudos mais aprofundados não indicam que elas sejam excludentes umas às outras.

A perspectiva das tendências integradoras "[...] compreende que os enfoques antecedentes não são excludentes, prevendo que as ações das organizações não eliminam necessariamente a proatividade dos indivíduos e vice-versa". (BORGES et al., 2010, p. 14).

Nessa linha raciocinativa, Taormina (1997) sugere uma definição mais abrangente de socialização organizacional. Destaca que a socialização organizacional é o modo por via do qual uma pessoa obtém competências profissionais relevantes, adquire um nível funcional de compreensão organizacional, alcança interações sociais de suporte com colegas de trabalho, e, geralmente, aceita as modalidades estabelecidas pela organização em particular. Para o autor, grande parte das variáveis pesquisadas nos estudos sobre socialização em organizações poderia ser agrupada em uma quantidade menor de classes. De efeito, propôs um modelo de socialização organizacional como um moto continuo composto por quatro domínios: 1) formação recebida; 2) compreensão (relativamente à organização); 3) suporte de colegas de trabalho; e (4) perspectivas futuras (na contextura da organização).

Para definir sua perspectiva de domínio, Taormina (1997) a descreve como uma esfera conceitual, na qual se encaixam as dimensões de socialização organizacional anteriormente pesquisadas. O domínio de formação se refere à transferência de conhecimentos relacionados ao trabalho de um membro veterano a um funcionário novato. $\mathrm{O}$ domínio compreensão se refere à percepção do empregado acerca do seu papel na organização, segundo seu funcionamento e objetivos. O terceiro domínio - o suporte de colegas de trabalho - reporta-se às atitudes dos veteranos ante a socialização do novato, e o último, perspectivas futuras, se relaciona com a visão de futuro que a pessoa guarda no novo contexto organizacional.

Borges et al. (2010) elaboraram um modelo de socialização cuja primeira aplicação conformou uma adaptação do questionário em inglês de autoria de Chao e colaboradores (1994). Os mesmos autores (2010) ressaltam que a literatura sobre socialização organizacional evoluiu muito, enfatizando principalmente a proatividade das pessoas e demandando estender-se o novo questionário a aspectos jamais abordados.

De tal sorte, foi criado o Inventário de Socialização Organizacional, privilegiando os aspectos: competência, proatividade, qualificação, domínio da linguagem, integração com as pessoas, objetivos e valores da organização, políticas, condições materiais de trabalho e história da organização.

Com base nos modelos elaborados por Chao et al. (1994), Taormina (1997) e Borges et al. (2010), elaborou-se um modelo para emprego neste estudo. Os itens escolhidos para elaboração do modelo proposto neste estudo (engajamento à instituição, integração às pessoas, domínio profissional e perspectivas futuras) procuraram agrupar o que se destacou como importantes para a socialização das pessoas nas organizações, enfatizando os enfoques desenvolvidos em pesquisas anteriores.

\section{PESSOAS COM DEFICIÊNCIA}

Nesta seção, abordam-se os conceitos acerca da deficiência, os aspectos legais e a realidade da Instituição de Ensino Superior onde o experimento foi efetivado.

\subsection{Deficiência - do conceito médico às elaborações sociais}

Instituído em 1981, o Ano Internacional das Pessoas com Deficiência marca, no 
Brasil, a necessidade de movimentos sociais organizados pelas próprias pessoas com deficiência e instiga reflexões para que se abandone o conceito de deficiência sob o ângulo da falta, perda ou diminuição funcional, para a compreensão social e afirmativa (LEITÃO, 2014). De acordo com o Manual de Legislação em Saúde da Pessoa com Deficiência (2006), existem diversos tipos de deficiência, dentre as quais se mencionam deficiência auditiva, intelectual, motora, visual e múltipla.

No Censo Demográfico realizado em 2010, as perguntas buscaram identificar as deficiências visual, auditiva e motora, e seus graus de severidade, por meio do percebimento da população sobre sua dificuldade de enxergar, ouvir e se locomover, mesmo com o uso do que é chamado de facilitadores, que são os óculos ou lentes de contato, aparelho auditivo, e a deficiência mental ou intelectual. Os resultados apontaram quase 46 milhões de pessoas que declararam ter pelo menos uma das deficiências investigadas, correspondendo a $23,9 \%$ do contingente demográfico brasileiro.

O IBGE (2010) enfoca que o conceito de deficiência se modificou na extensão do tempo. Anteriormente, a abordagem acompanhava o modelo médico. Hoje, existe a Classificação Internacional de Funcionalidade, Incapacidade e Saúde - CIF, que entende a incapacidade como resultante de uma limitação, tanto das funções e estruturas do corpo, quanto da influência de fatores sociais e ambientais sobre essa limitação.

A Convenção sobre os Direitos das Pessoas com Deficiência e Protocolo Facultativo (BRASIL, 2011, p.5) estabelece que "[...] pessoas com deficiência são aquelas que têm impedimentos de natureza física, intelectual ou sensorial, os quais, em interação com diversas barreiras, podem obstruir sua participação plena e efetiva na sociedade com as demais pessoas".

Compreende-se que "[...] as deficiências são construções sociais" (LEITÃO, 2014, p. 21) e que não é o limite individual que determina a deficiência, mas sim as barreiras do meio físico, do transporte, da informação, da comunicação e dos serviços (BRASIL, 2011).

Sassaki (2010) relembra que a história da profissionalização daqueles com deficiência passou por diversas fases. No período da exclusão, era negado acesso ao mercado de trabalho às pessoas com deficiência, pois se pensava que pô-las para trabalhar significava explorá-las. Acreditava-se, também, que a deficiência era um impeditivo ao trabalho. Na fase da segregação, as pessoas com deficiência eram postas em instituições educacionais filantrópicas que tinham parceria com empresas privadas e estas iriam trabalhar dentro das instituições ou em suas residências, afastando-as do convívio social trabalhista. Cria-se que se estava protegendo quem tinha deficiência. No período da integração, várias vagas de trabalho eram postas à disposição das pessoas com deficiência, no entanto, não havia nenhuma reestruturação ambiental ou cultural da empresa para receber os novos empregados. Dessa maneira, os trabalhadores com deficiência tinham dificuldade em se envolver em programas de treinamento e desenvolvimento por falta de acessibilidade ou mesmo integração com outros empregados. Finalmente, veio a inclusão, quando empregadores, instituições formadoras e pessoas com deficiência devem enfrentar juntos os desafios da qualificação, da produtividade e da competitividade (ARAÚJO; SCHMIDT, 2006). Esses outros períodos não foram completamente abolidos e algumas atitudes ainda coexistem.

Hoffmann, Traverso e Zanini (2014) argumentam que a relação entre as pessoas com deficiência e o acesso ao mundo do trabalho configura história recente, pois entendem esta história como marcada no ano de 1981, quando foi declarado o Ano Internacional da Pessoa Deficiente pela Organização Mundial das Nações Unidas e que, posteriormente, tal movimento se refletiu na Constituição de 1988, ao cuidar de temas relevantes, como acessibilidade, trabalho e educação relacionados às pessoas com deficiência.

Depois da Constituição de 1988, houve várias conquistas relacionadas a direitos e a inclusão das pessoas com deficiência no mercado de trabalho. Malgrado os progressivos 
avanços em relação aos direitos e legislação relacionados às pessoas com deficiência, a participação ativa destas na sociedade, com plena inclusão na esfera do trabalho, ainda se exprime bem distante da esperada (LIMA; JURDI, 2014).

\subsection{Aspectos legais}

Araújo e Schmidt (2006) relatam que a Constituição Brasileira de 1988 e a Lei 8.213, de 24 de julho de 1991, são os principais documentos que garantem às pessoas com deficiência o direito de acesso ao mercado de trabalho, tanto oficial quanto particular. A Constituição Federal proíbe a discriminação no que se refere a salários e critérios de admissão para os trabalhadores com qualquer tipo de deficiência (art. 7, XXXI) e destinou a reserva de $20 \%$ de cargos e empregos públicos àqueles com deficiência (art. 37, VIII).

A regulamentação do art. 37, VIII, da Constituição Federal, ocorreu com as Leis $7.853 / 89$ e $8.112 / 90$, tendo a segunda, efetivamente, assegurado às pessoas com deficiência física o direito de se inscreverem em concursos públicos, reservando-lhes um percentual das vagas destinadas à ocupação dos cargos e empregos públicos.

A Lei de Cotas ( $n^{0} 8.213$, de 24 de julho de 1991) "[...] surgiu como uma ação afirmativa para a inserção de pessoas com deficiência no mercado de trabalho, havendo um percentual de vagas a serem preenchidas por pessoas com deficiência em empresas do setor privado e também do setor público". (BRASIL, 1991). Com efeito, no Brasil, a Lei de Cotas contribuiu para ampliar as possibilidades de ingresso de pessoas com deficiência no mercado de trabalho. Empresas com até 200 funcionários devem ter dois por cento dos lugares preenchidos por pessoas com deficiência, de 201 a 500 funcionários, 3\%; de 501 a 1000 empregados, $4 \%$, e organizações de mais de 1001 funcionários, 5\% das vagas (ARAÚJO; SCHMDIT, 2006).

Para as pessoas com deficiência que tencionavam ingressar no mercado de trabalho, a obrigatoriedade resultante da Lei de Cotas fez com que as empresas começassem a contratar profissionais com deficiência. As organizações, entretanto, iniciaram a execução das contratações sem nenhum tipo de planejamento, o que dificultou a socialização de pessoas com diferença funcional (dicção empregada por Carvalho-Freitas) no ambiente organizacional. Várias foram as barreiras que dificultaram a inclusão de pessoas com deficiência no âmbito laborativo. Aí, então, se incluem o decurso histórico de segregação, a falta de acessibilidade e barreiras culturais (HAMMES; NUERNBERG, 2015).

Conquanto haja sido editada a Lei das Cotas, as empresas ainda expressam dificuldades relacionadas ao cumprimento da cota, e o número de pessoas com deficiência contratadas ainda está abaixo do que está definido na legislação (SILVA; PRAIS; SILVEIRA, 2015). Dados do Ministério do Trabalho e Emprego apontam que, em 2015, no Brasil, de um total de 48.060.807 vínculos, em empresas da Administração Pública, Empresa Pública e Sociedade de Economia Mista e demais tipos de naturezas jurídicas, 403.255 eram de trabalhadores com deficiência, perfazendo um total de $0,84 \%$ do total de vínculos, em que 93,34\% dos trabalhadores com deficiência estavam empregados em ocupações com obrigação legal e $6,66 \%$ noutros sem cobertura de obrigação legal.

Leitão (2014) enfatiza, no entanto, que, para ocorrer qualquer inclusão social, a acessibilidade é a condição fundamental e imprescindível. Araújo e Schimtt (2006) relatam que, entre os obstáculos relacionados ao não cumprimento das cotas de funcionários com deficiência, encontram-se limitações físico-estruturais, dificuldades de adaptação do funcionário à organização e/ou ao trabalho em si. Também relacionam à baixa qualificação das pessoas com deficiência e ao preconceito daquelas envolvidas no processo, entre outros aspectos. 


\subsection{Pessoas com deficiência - a realidade da IFES investigada}

A IFES investigada é uma Autarquia Federal de Regime Especial vinculada ao Ministério da Educação, cuja finalidade é, entre outras, formar profissionais qualificados. Contava em 2017 com 2.166 docentes, 3.420 técnico-administrativos e 26.512 alunos matriculados no primeiro semestre e, começou a se preocupar com a inclusão de pessoas com deficiência quando foi inserida, mediante a Lei 8.112, de 11 de dezembro de 1990, a reserva de $20 \%$ das vagas em concurso para pessoas com deficiência. Naquele momento, se começou a pensar em ações que viabilizassem a inclusão de pessoas com deficiência, no entanto, ainda não se refletia no verdadeiro sentido da palavra. Anteriormente, era realizada a integração de pessoas com deficiência aos quadros da instituição.

Nos últimos anos, é visualizada uma série de ações e de atividades desenvolvidas, a fim de mostrar a importância da inclusão e da acessibilidade das pessoas com deficiência, seja na educação, no trabalho ou na comunidade (PERLIN et al., 2016).

Dessa maneira, o ingresso de alunos e servidores com deficiência no ambiente das universidades cresceu bastante à extensão do tempo. Apesar de o ingresso no Ensino Superior ser um direito, muitas são as barreiras enfrentadas pelas pessoas com deficiência. Compreende-se como barreira "[...] qualquer entrave ou obstáculo que limite ou impeça o acesso, a liberdade de movimento, a circulação com segurança e a possibilidade de as pessoas se comunicarem ou terem acesso à informação". (BRASIL, 2004).

A extensão da legislação brasileira no tocante às políticas públicas dirigidas a pessoas com deficiência fez surgir muitos programas por parte do Governo Federal. Um deles foi o Programa Incluir, do Ministério da Educação (MEC/SESu), criado em 2005, que convocou as Instituições Federais de Ensino Superior (IFES) ao compromisso com a inclusão educacional de pessoas que denotem alguma condição de deficiência. Este fato impulsionou as IFES a verificarem suas condições de acessibilidade (LEITÃO, 2014).

Em 2010, a IFES investigada inaugurou um setor específico para elaborar ações relativas à inclusão de pessoas com deficiência, a Secretaria de Acessibilidade, que tinha como objetivo elaborar, executar e gerenciar ações, oferecer suporte às unidades acadêmicas e administrativas para a efetivação da acessibilidade, bem como estimular o desenvolvimento de uma "cultura inclusiva" na Instituição (LEITÃo, 2014). A Secretaria de Acessibilidade não está diretamente vinculada à Pró-Reitoria da Gestão de Pessoas, mas auxilia em aspectos relacionados a lotação e inclusão de servidores com deficiência.

Em pesquisa realizada em 2015 pela Secretaria de Acessibilidade, verificou-se que havia 103 servidores com deficiência na IFES investigada. Em 2017, esse quantitativo aumentou, chegando a 114 nas expressas condições. Destes, 31 denotam deficiências relacionadas a visão, 29 deficiência auditiva, 23 mobilidade reduzida, além de três servidores com amputação, seis com deformidade congênita, dois hemiparesia, seis monoparesia, cinco monoplegia, três paraparesia, três paraplegia, um tetraparesia e um possui deformidade congênita.

Percebe-se que, em relação aos três tipos de deficiência encontrados na IFES, o quantitativo se mantém equivalente. Segundo o levantamento realizado pela Secretaria de Acessibilidade, a instituição possui 29 deficientes auditivos, 31 visuais e 30 servidores com deficiência motora ou física. Não foi encontrado nenhum com deficiência intelectual.

Verifica-se que o Centro de Humanidades é a grande unidade que exprime um quantitativo maior de servidores com deficiência, em 2017, com 17 servidores. Na sequência, vem o Hospital Universitário, com dez trabalhadores com deficiência, seguidos pela PróReitoria de Planejamento e Administração e pela Pró-Reitoria da Gestão de Pessoas, ambas com nove servidores denotando diferença funcional. A Biblioteca Universitária e o Instituto de Cultura e Arte apareceram com sete servidores. A Faculdade de Medicina e o Centro de 
Tecnologia registram seis servidores. Outros setores expressaram números menores de funcionários com deficiência. O Centro de Humanidades possui maior quantitativo com deficiência por contar com o Departamento de Letras/Libras, que abrange o curso de graduação de mesmo nome e que possui vários professores surdos.

Evidencia-se a diversidade de deficiências encontradas na instituição, com variadas gradações, fato este que requer do órgão a conscientização da necessidade de aprimoramento da adaptação, tanto dos trabalhadores com deficiência quanto do restante dos funcionários técnico-administrativos e docentes, para que dificuldades de relacionamento no trabalho e acessibilidade sejam minimizadas.

\section{PROCEDIMENTOS METODOLÓGICOS}

Para o desenvolvimento da pesquisa sob relato, adotou-se a abordagem qualitativa e perfilhou-se o estudo de caso, com vistas a examinar as percepções de pessoas com deficiência sobre a socialização organizacional em uma Instituição Federal de Ensino Superior. O estudo de caso - ensina Godoy (2010) - é uma possibilidade de pesquisa que tem como característica a busca por significados atribuídos pelos sujeitos às suas vivências e experiências.

Com efeito, percebeu-se que as características do estudo de caso se mostram adequadas aos objetivos a serem alcançados neste ensaio, motivo por que se optou por estudar caso único, pois o locus do exame é caracterizado como uma Instituição Federal de Ensino Superior, e a demanda de teor acadêmico foi efetuada com servidores que possuem deficiência.

Nesta investigação, foi considerada a perspectiva da socialização organizacional, tomando como referencial os modelos teóricos de Chao et al. (1994), Taormina (1997) e Borges et al. (2010). Para tanto, foram definidos quatro domínios: (1) Engajamento à instituição; (2) Integração às pessoas; (3) Domínio profissional; e (4) Perspectivas futuras. Esse modelo configura-se, portanto, como uma proposta para análise da Socialização Organizacional, porquanto pretendeu delinear um modelo que privilegiasse, abrangentemente, as dimensões ocorrentes nos experimentos anteriores.

O universo desta pesquisa foi composto por 114 pessoas com deficiências que trabalham em uma Instituição Federal de Ensino Superior na cidade de Fortaleza, Ceará. A amostra foi do tipo não probabilística ou por conveniência, a depender da disponibilidade e aceitação dos servidores em participar. Foram entrevistados 15 servidores com deficiência da Instituição investigada.

Alvos de entrevista foram os servidores com deficiência auditiva, motora, visual e múltiplas. Não foram encontrados servidores com deficiência intelectual, tais como pessoas com transtorno de espectro altista pelo fato de ainda não terem aberto concurso para esta categoria, até o momento da pesquisa.

A amostra foi composta por $60 \%$ de homens e $40 \%$ de mulheres. Destas, $33,33 \%$ possuem deficiência física, 26,66\% têm deficiência visual, 33,33\% expressam deficiência auditiva em distintas gradações e 6,6\% denotam deficiência múltipla. Dos entrevistados com deficiência física, $13,33 \%$ são tetraplégicos, $6,6 \%$ são paraplégicos, $6,6 \%$ têm deformidade congênita ou adquirida e 6,6\% têm monoparesia. Dos servidores com deficiência visual, $13,33 \%$ são cegos, $6,6 \%$ têm baixa visão e 6,6\% visão parcial, ou seja, baixa visão de um olho. Dos servidores com deficiência auditiva, $20 \%$ são surdos, $3,33 \%$ têm surdez bilateral - e fizeram o implante coclear - e 6,6\% têm deficiência múltipla.

Para a recolha dos indicadores, recorreu-se entrevista, utilizando-se de um roteiro semiestruturado de perguntas. Para o tratamento dos dados, aplicou-se o método de análise de conteúdo que "[...] é um conjunto de técnicas de análise das comunicações”. (BARDIN, 2011, 
p.37).

Considerando os objetivos específicos e as quatro categorias de análise, foram definidas as respectivas unidades de contexto e unidades de registro, para, em seguida, serem inseridas no Atlas ti, com os documentos primários (entrevistas) visando a selecionar as unidades de registro (quotations). As unidades de contexto foram elaboradas a priori, no entanto, à medida que as entrevistas foram realizadas, as unidades de contexto foram objeto de algumas modificações, pois, como explicado em passagem anterior, esta é uma característica das pesquisas cujas categorias são de grade mista. Para exame dos dados, valeuse do software ATLAS ti, versão 8.0.

\section{RESULTADOS}

No seguimento estão os resultados da pesquisa, com base nas dimensões: engajamento à instituição, integração às pessoas, domínio profissional e, perspectivas futuras. A visualização dos resultados de cada categoria foi realizada com auxílio da ferramenta Network Views, do software adotado, utilizado para a análise dos dados - o ATLAS ti 8.0 em que estão descritas as citações ocorrentes para cada unidade de registro da busca sob relato. As unidades de contexto e as suas respectivas unidades de registro são conectadas por meio de setas. Cada código é indicado com um par ordenado de dois números, em que o primeiro representa a frequência do uso da unidade de registro, referindo-se ao total de citações em que o código foi relacionado e, o segundo quantitativo representa a densidade do código, ou seja, o número de outros códigos aos quais ele está relacionado.

\subsection{Dimensão engajamento à instituição}

A primeira unidade de contexto a ser observada na dimensão Engajamento à Instituição é o conhecimento da instituição, a qual demonstra o quanto o servidor dela conhece. A unidade de registro mais encontrada no quesito conhecimento da instituição foi história. Por história, entende-se "[...] quanto o indivíduo percebe a identidade organizacional por meio do conhecimento de sua história, suas tradições e sua cultura". (BORGES et al., p.15, 2010).

Figura 1 - Engajamento à instituição

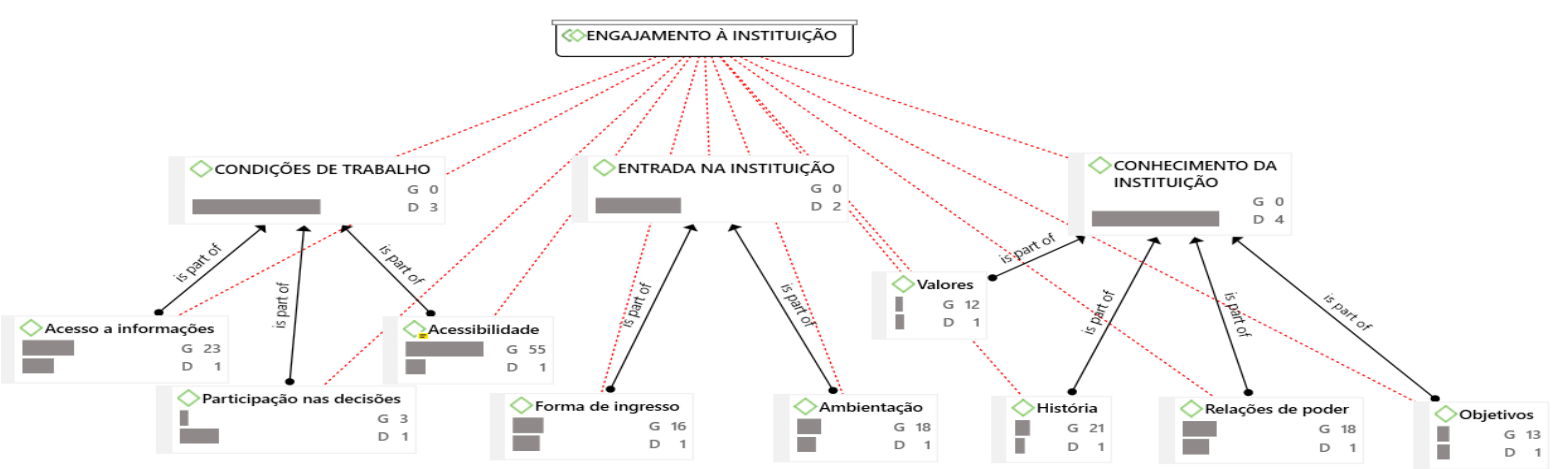

Fonte: Dados da pesquisa.

As respostas evidenciaram que cinco servidores conheciam a história da IFES, sentiam-se atraídos pela instituição desde jovens, consideravam-na conceituada e uma das melhores do Norte e Nordeste; mas também mostram que seis servidores não conheciam a história da instituição e quatro só a conheciam em parte. Também mostrou que os servidores sentem falta de programas de inclusão para as pessoas com deficiência dentro da instituição, como existem em muitas empresas privadas.

Um entrevistado relata: 
Eu conheço a história da IFES, na época não tinha inclusão. Também não tinha Secretaria de Acessibilidade, mas eu lutei para colocar inclusão, arrumar relação social. (E7)

Com relação aos valores, assim como no item história, cinco dos entrevistados afirmaram não conhecer os valores da instituição, dois relataram aprender no dia a dia e dois dos entrevistados mencionaram os valores contidos no Código de Ética do Servidor Público Federal como sendo valores da instituição.

Chao et al (1994) ressaltam que uma das dimensões incorporada na maioria das definições de socialização é a aprendizagem de objetivos e valores organizacionais específicos. Ele explica haver Schein argumentado que a socialização inclui a compreensão das regras e princípios que mantêm a integridade da organização. Dentre os objetivos e valores a serem aprendidos estão aqueles não escritos, informais e tácitos. Embora os servidores não tenham consciência ou não saibam dizer quais os valores da instituição, estes estão sendo vivenciados e aprendidos ao serem repassados dos servidores mais antigos aos mais novos dentro da instituição.

Com relação aos objetivos, foi perguntado se os entrevistados conheciam os objetivos da instituição. Foram obtidas 13 quotations de 13 respondentes. Destes, sete afirmaram conhecer e seis dissertam não saber quais eram os objetivos. Só tinham uma ideia do objetivo geral.

A pergunta relacionada ao item relações de poder foi se o entrevistado tinha percepção das relações de poder existentes na IFES e se eles sabiam a quem procurar quando precisavam de algo. Houve 18 menções relacionadas a este item. Dos 15 entrevistados, dez disseram ter percepção das relações de poder e saber a quem procurar quando precisavam de algo. Dois afirmaram não conhecer, um posicionou-se no meio-termo e um declarou saber a quem procurar, mas que não burlava processos. Apesar das relações de amizade, cumpria os processos burocráticos. O conceito de poder foi interpretado de várias maneiras. Uma destas derivou do trabalho de Marx Weber e tratou o poder como modalidade de dominação e outra decorreu dos estudos organizacionais, no âmbito dos quais o poder é distribuído na estrutura das organizações formais, ou seja, os arranjos não são modos de dominação, mas autoridade formal, legítima e funcional. (DOUGHERTY et al, 1996) Esta é, pois, a perspectiva que é abordada na pesquisa.

A segunda unidade de contexto relacionada à dimensão Engajamento à instituição refere-se à entrada na instituição, a qual mostra de que maneira os servidores ingressaram: cotas ou ampla concorrência, e o modo como os servidores são recebidos pela instituição - se ela organiza ou não um seminário de ambientação, se os servidores participam do seminário antes de sua lotação ou somente depois, duração do seminário, se há um treinamento específico para a realização das suas funções e se existe um programa de tutoria.

As duas unidades de registro relacionadas à entrada na instituição são: forma de ingresso e ambientação. Destas, ambientação foi a que obteve maior número de menções. Percebe-se é que, antigamente, os servidores eram convocados, se apresentavam e começavam a trabalhar. Somente depois de um tempo, é que eles faziam o Seminário de Ambientação. Consoante as palavras dos entrevistados, essa prática mudou. Hoje os servidores participam de um Ato de Posse com o comparecimento do Reitor e, no mesmo dia, participam do Seminário de Ambientação, contando com intérpretes, caso estejam ingressando servidores surdos. Somente depois do Seminário é que eles começam a trabalhar na instituição.

Santos et al. (2017) revelam que criar um espaço de acolhimento quando o servidor ingressa em um novo locus organizacional, em que este possa dialogar sobre a sua nova situação, sentimentos iniciais no trabalho e perspectivas pode ser um trabalho fundamental para os que exercem atividades na área da Gestão de Pessoas nas organizações. 
A terceira unidade de contexto da dimensão Engajamento à instituição se refere às condições de trabalho e busca verificar como acontece o acesso às informações, se há participação dos servidores nas decisões tomadas pela instituição, procura verificar questões como acessibilidade, e nesta inclui dificuldades e avanços encontrados pelos servidores.

Pelo que se percebe, a unidade de contexto com maior número de citações se refere às condições de trabalho e a unidade de registro foi acessibilidade. Isso demonstra que as pessoas com deficiência, servidores da IFES investigada, enfrentaram e ainda enfrentam muitos problemas no ambiente organizacional.

Nesse item, foram tratados pontos como: os telefones que são comprados por licitação; horários de trabalho; demora de implantação e funcionamento dos elevadores, falta de acessibilidade; lotação inadequada à sua deficiência; dificuldade de tocar a cadeira de rodas em um piso inadequado; rampas que, embora adequadas às normas, não são adaptadas a um tetraplégico; e amplitude de algumas áreas da instituição sem pontos fixos e sem pisos táteis para facilitar a vida dos deficientes visuais; falta de acessibilidade nos banheiros; dificuldade de encaixe da cadeira de rodas à mesa no Restaurante Universitário; programas de pós-graduação que não têm reserva de vagas para pessoas com deficiência; falta de valorização da gestão de pessoas com deficiência; quantidade insuficiente de intérpretes; falta de acessibilidade dos sistemas administrativos; falta de conhecimento e conscientização ao trabalhar com profissionais com deficiência.

Um dos problemas mencionados está no elevador que demorou a ser implantado e, depois que foi instalado, fica muito tempo parado por falta de licitação da empresa que realiza a manutenção.

O problema do elevador é que ele fica muito em manutenção. Ele passa a maior parte do tempo na verdade em manutenção. Não existe uma iniciativa boa pra que aquilo ali funcione sempre, para que aquilo ali sempre permaneça em atividade. Que eu precise ir no primeiro andar e possa ir tranquilo sem precisar pedir a alguém. Dessa forma assim. (E1)

A unidade de registro acesso às informações obteve 23 citações relevantes. Foi perguntado se os entrevistados tinham acesso fácil às informações dentro do ambiente organizacional. Entre os respondentes, dez afirmaram obter acesso a informações por meio do site da instituição, internet, telefone, circulares, emails e tecnologias assistivas, como o NVDA e o DOSVOX. Os servidores cegos mencionaram problemas como dificuldade de leitura por meio dos programas de tecnologia assistiva quando o documento é salvo em imagem. Relataram que, às vezes, num mesmo setor, servidores salvam em formato diferente. O leitor lê pdf, mas não quando o documento é salvo como imagem. Nem o DOSVOX tampouco o NVDA conseguem ler no formato de imagem, mesmo que o conteúdo seja textual.

Com relação à participação nas decisões, poucos servidores opinaram sobre este item, porque, inicialmente, ele não fazia parte do conjunto de unidades de registro selecionado. Surgiu espontaneamente durante as entrevistas e verificou-se que, atualmente, na instituição, durante a formulação do PDI - Plano de Desenvolvimento Institucional - as opiniões dos três segmentos (docentes, servidores técnico-administrativos e alunos) foram ouvidas, tendo sido isto relatado nas entrevistas.

\subsection{Dimensão integração às pessoas}

Essa dimensão tem como unidades de contexto os seguintes itens: chefia e colegas e, aceitação e discriminação. As unidades de registro relacionadas a estas unidades de contexto são: confiança, conhecimento mútuo, encontros sociais, inclusão, discriminação, relação com a chefia, relação com colegas de trabalho, relação com subordinados e terminologia. 
Figura 2 - Integração às pessoas

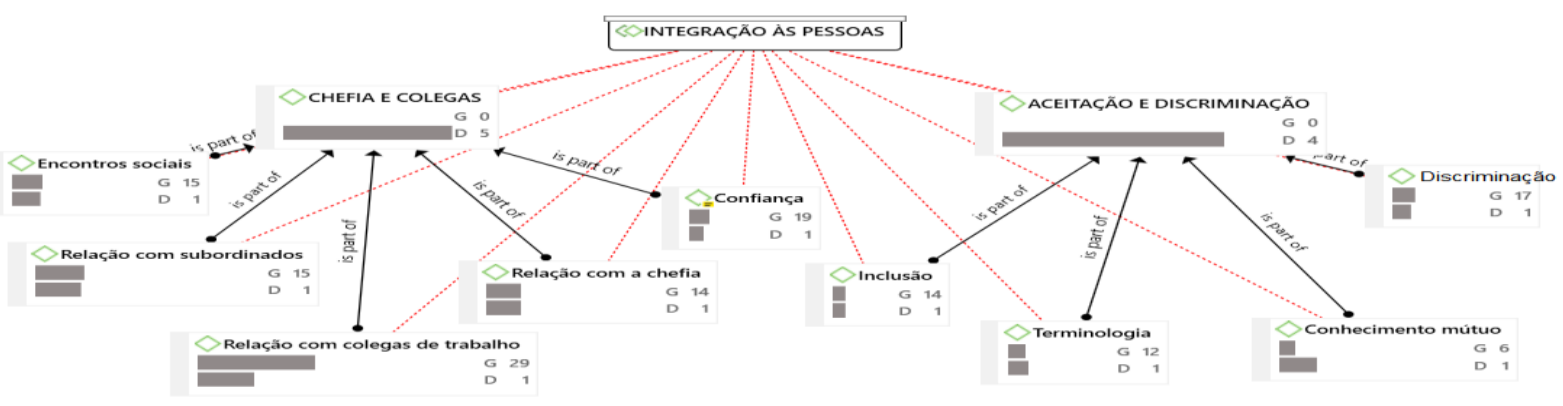

Fonte: Dados da pesquisa.

A primeira unidade de contexto da dimensão integração às pessoas é chefia $e$ colegas, a qual reúne como ocorrem as relações com chefia, colegas de trabalho, com subordinados, relações de confiança entre colegas e se acontecem encontros com colegas de trabalho fora da instituição

A unidade de registro com maior número de menções foi relação com colegas de trabalho. Relativamente aos colegas de trabalho, observou-se que predomina um bom convívio e qualificada ajuda entre os pares. Pesquisas nessa área exprimem que os aspectos informais da socialização, como o convívio diário com outras pessoas, são sobradamente importantes para a adaptação e aprendizagem na organização (BORGES e ALBUQUERQUE, 2014; CARVALHO-FREITAS et al., 2010).

Quando especificada a pergunta em relação à chefia, os 15 servidores falaram ter boa relação, no entanto, três deles ressaltaram que poderia melhorar. Um entrevistado reclamou de a chefe chamar de outra sala e ele ter dificuldades pra ouvir; outro expressou que poderia melhorar a comunicação por ser surdo e sempre precisar de um intérprete de libras; uma, ainda, disse ter tido dificuldades, pois o chefe não sabia o que fazer com ela em razão de sua deficiência visual, mas que, superado o primeiro momento, se adaptou ao ambiente e às suas funções. A própria servidora tomou a iniciativa com relação a dizer o que poderia fazer no seu setor. Ela mesma contribuiu para sua socialização, uma vez que a chefia e a instituição não estavam preparadas para receber uma pessoa com deficiência visual.

No que respeita a subordinados, oito relataram ter boa relação, três disseram não ter subordinados e uma expressou ter alguns problemas de relacionamento. No que concerne à unidade de registro confiança, neste estudo, se nota a existência de relações de confiança entre os pares na contextura institucional.

$\mathrm{Na}$ unidade de registro encontros sociais, foi indagado aos entrevistados se eles costumavam sair com colegas de trabalho fora da instituição. Oito responderam que sim. Um deles já tinha amizade com eles por serem da comunidade surda. Dois disseram que não mais, pois já tiveram problemas no seu setor. E um disse sair somente com colegas de outros setores.

A segunda unidade de contexto a ser observada na dimensão integração às pessoas é aceitação e discriminação, na qual constam aspectos relacionados a inclusão e aceitação das pessoas com deficiência. Abordam aspectos como conhecimento sobre vida pessoal, preconceito, terminologia utilizada para se referir às pessoas com deficiência. As unidades de registro encontradas foram as seguintes: inclusão, conhecimento mútuo, terminologia e discriminação. Quem demonstrou maior número de menções foi a unidade de registro discriminação.

Das 12 pessoas que responderam, todos disseram não ter sofrido discriminação. As pessoas com deficiência passam a vida sofrendo diversas modalidades discriminatórias, mas, na instituição investigada, elas nunca passaram por este tipo de situação. Embora não tenha sido relatado nas entrevistas, no entanto, muitos gestores ainda resistem em receber pessoas 
com deficiência nos seus setores, fato este corroborado por Carvalho-Freitas (2008), ao apontar dificuldades para inserir e gerir o trabalho das pessoas com deficiência: as maneiras como os gestores veem a deficiência, o jeito de adequar as condições e práticas de trabalho e a necessidade de compreender a satisfação dos profissionais no mercado laboral.

No que é pertinente à inclusão, os 15 servidores expressaram se sentirem incluídos e aceitos no ambiente organizacional. Foi relatado, ainda, o fato de que muitos servidores se tornam amigos e isso faz o ambiente organizacional um lugar bom de se conviver, uma vez que eles passam a maior parte de suas vidas na instituição.

Em relação a conhecimento mútuo, a maior parte dos entrevistados compartilha informações relacionadas à vida pessoal. Este compartilhamento revela a efetividade do clima de confiança.

Com atinência à terminologia, a maioria dos servidores revelou não ter problemas relacionados a esse fator. Eles têm consciência dos termos empregados à medida do tempo e dizem que, hoje, há um respeito e as pessoas em geral falam o que é politicamente correto.

\subsection{Dimensão domínio profissional}

A terceira categoria busca informações relacionadas à dimensão domínio profissional. Foram trabalhadas as unidades de contexto competência e qualificação. São unidades de registro relacionadas à unidade de contexto competência: atitudes, domínio da linguagem e domínio das tarefas. São vinculadas à unidade de contexto qualificação: experiências profissionais anteriores, participação em treinamentos e educação formal.

Figura 3 - Domínio profissional

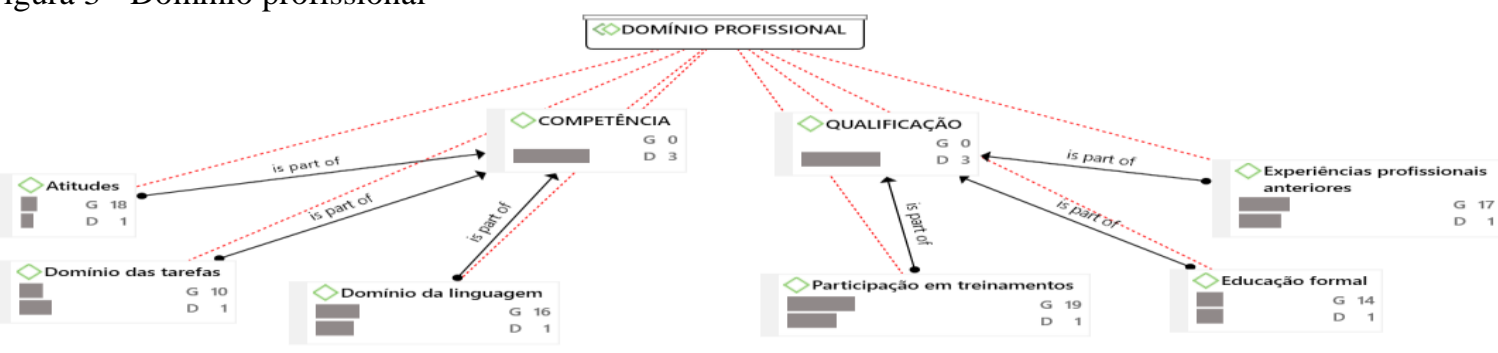

Fonte: Dados da pesquisa.

A primeira unidade de contexto a ser observada nesta dimensão é competência, a qual tenta descobrir habilidades e competência do servidor. A unidade de registro que obteve mais menções foi atitudes. Em condições desfavoráveis, a diferenciação entre competência e qualificação vinculada às condições de trabalho pode ficar mais evidenciada, pois, mesmo que as pessoas estejam preparadas para o desempenho, sem as condições adequadas de trabalho, a competência dessas pode não se concretizar ou ser minimizada. $O$ servidor pode até ser qualificado, ter proatividade, querer fazer um bom trabalho, mas, se não tiver as condições adequadas, não conseguirá atingir o seu objetivo (BORGES, ROS-GARCIA, TAMAYO, 2001; BORGES et al., 2014).

Com referência às atitudes, as respostas foram bem variadas. Foi indagado sobre as características que o entrevistado achava possuir na qualidade de servidor público. Predominaram nas respostas compromisso, responsabilidade, proatividade, ética, domínio das tarefas, tentativa de bom atendimento aos alunos surdos e compreensão. Dentre as respostas também foram mencionadas dificuldades de liderança.

Muitas pesquisas relatam as ações dos próprios sujeitos a socialização e assumem a noção de que as pessoas, ao ingressarem nas organizações, tencionam que esta entrada aconteça da melhor maneira possível e, com efeito, se motivam, proativamente, para estabelecerem a própria inserção organizacional (BORGES et al., 2014). Isto quer dizer que 
os servidores se sentem motivados a ajudarem no seu processo de socialização organizacional, pois querem se sentir aceitos e incluídos no seu ambiente organizacional.

No que respeita à unidade de registro domínio da linguagem, o resultado mostrou a existência de servidores que, apesar de trabalharem já há algum tempo na instituição, ainda não conhecem as siglas utilizadas, principalmente, relacionadas à Pró-Reitoria da Gestão de Pessoas - PROGEP.

Todos os servidores garantiram dominar suas tarefas, perguntados diretamente ou não. Informaram ter compromisso e proatividade na realização de suas funções, assim como preocupação com a melhoria da instituição. Asseveraram, no entanto, que a pessoa tem de se superar, fazer dobrado, para se mostrar capaz.

Finalizando a categoria domínio profissional, a segunda unidade analisada foi a qualificação, na qual constam a formação profissional da pessoa com deficiência na instituição, experiências profissionais anteriores e participação em treinamentos. A qualificação consiste num conjunto de ações em que os trabalhadores se apropriam de toda a produção, utilizando sua criatividade e potencialidades, não apenas repetindo ações quase autônomas. Ainda que o controle do capital exista, os trabalhadores são capazes de constituir um saber coletivo a respeito do trabalho que pensam e executam (MANFREDI, 1998).

No mundo do trabalho, "[...] a qualificação apresenta-se como entrave para as pessoas com deficiência conseguirem emprego" (MOREIRA et al., 2011), no entanto, na instituição estudada, verifica-se que os servidores com deficiência denotam elevada qualificação. Um servidor está cursando doutorado, um tem o Mestrado concluído, quatro possuem ou estão cursando a Especialização, sete têm nível superior completo ou incompleto e dois servidores entrevistados possuem apenas o ensino médio. Observa-se que esse antagonismo acontece em virtude de os servidores serem concursados. São pessoas que se dedicaram ao estudo para passar em um concurso e não querem ou não quiseram parar de estudar. Isto é diametralmente distinto do ocorrente na iniciativa privada e das dificuldades encontradas pelas pessoas com deficiência em concluir o ensino formal.

A unidade de registro que apontou mais menções referentes à unidade de contexto qualificação foi participação em treinamentos, com 19 citações. Percebe-se que os servidores têm interesse em participar dos treinamentos oferecidos pela instituição, e muitos participam realmente. Os que não o fazem relatam ser em razão de estarem cursando a graduação. A participação em treinamento é parte das estratégias utilizadas pelas empresas para socialização de seus funcionários. Nota-se que a instituição se preocupa com a qualificação de seus funcionários, oferece treinamentos diversos e o servidor solicita a participação por meio do Sistema Integrado de Gestão, Planejamento e Recursos Humanos - SIGPRH (Recursos Humanos) e a solicitação é submetida à chefia imediata para homologação.

$\mathrm{O}$ treinamento constitui uma das primeiras modalidades utilizadas para a socialização de membros admitidos a uma organização. Faz parte das chamadas táticas organizacionais utilizadas pelas organizações para integrar os novos membros a um novo ambiente ou membros veteranos a um novo setor ou nova demanda de serviços. Esta informação é corroborada por Andrade et al. (2012), ao acentuarem que, no enfoque das táticas organizacionais, o foco é centrado nas ações da organização que visam a facilitar a socialização dos funcionários então admitidos.

$\mathrm{Na}$ unidade de registro educação formal, dos 15 entrevistados, apenas dois possuem somente o ensino médio, o que indica o alto nível de qualificação das pessoas com deficiência da instituição sob exame. Destes, um possui o técnico em mecânica. Somente um dos entrevistados mencionou dificuldades de concluir o ensino fundamental e médio, tendo iniciado o curso superior aos 46 anos. Hoje ele é professor da instituição.

Perguntados sobre experiências profissionais anteriores, sete servidores mencionaram ser a instituição o seu primeiro ou segundo emprego formal. Enfatiza-se aqui a 
dificuldade de inserção no mercado formal para pessoas com deficiência, mas salienta-se também que eles tentam ganhar o próprio sustento atuando em trabalhos informais e estudando para ingressar no mercado mediante concurso público ou atuando em empresas privadas.

\subsection{Dimensão perspectivas futuras}

A quarta categoria procura identificar os aspectos relativos à dimensão perspectivas futuras. Este domínio foi dividido em perspectivas internas e perspectivas externas. Esta dimensão procura identificar o que os servidores com deficiência pensam com relação ao seu futuro dentro da instituição, ou mesmo fora dela. As unidades de registro relacionadas às perspectivas internas são: aperfeiçoamento, valorização/oportunidades, inovações e insegurança. As relacionadas às perspectivas externas são: aposentadoria e passar em outro concurso.

Figura 4 - Perspectivas futuras

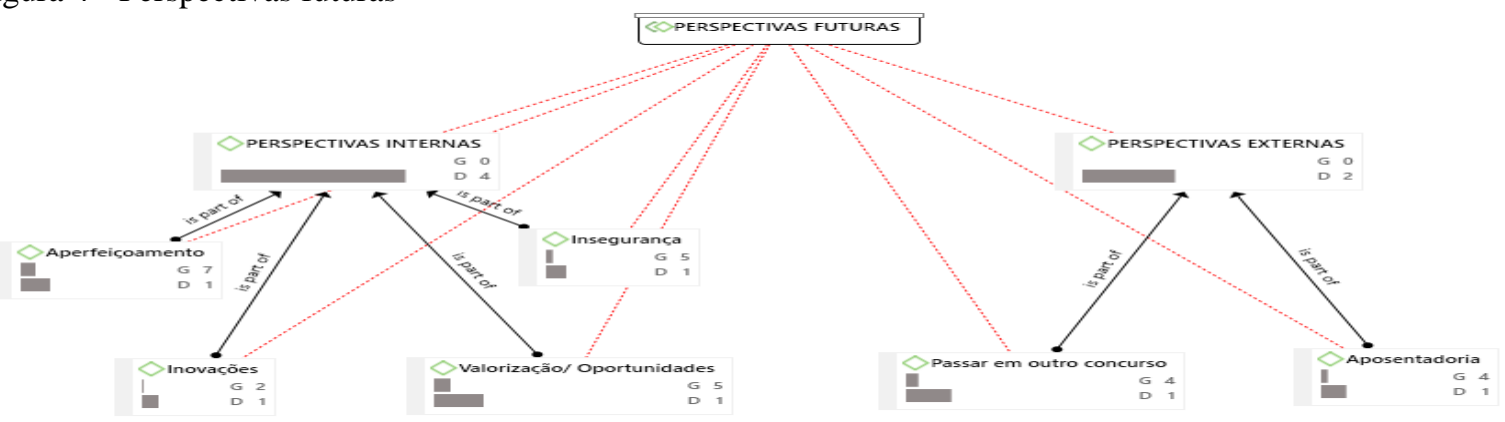

Fonte: Dados da pesquisa.

A primeira unidade de contexto a ser observada é a unidade perspectivas internas, a qual reúne o que as pessoas com deficiência esperam do seu futuro dentro da instituição. Das perspectivas internas, a unidade de registro que obteve mais menções foi aperfeiçoamento, comprovando a preocupação dos servidores em querer se qualificar. A qualificação está dentro das ações formais da organização para socialização de seu quadro de pessoal. Genari, Ibrahim e Ibrahim (2017) enfatizam que atividades relacionadas à capacitação dos profissionais promovem o aumento da satisfação com o trabalho desenvolvido, a redução da ansiedade e a intenção de permanecer na empresa.

De acordo com as respostas, nota-se que os servidores pretendem continuar se qualificando, até para melhorar seu nível salarial. "As empresas, por sua vez, atuam em um mercado no qual o capital humano de qualidade é fator de diferenciação. Para manterem-se atuantes e competitivas, é necessário que sejam compostas por pessoas qualificadas para o exercício das atividades". (PHILERENO et al., 2015, p. 161). Desse modo, a qualificação profissional, segundo Philereno et al. (2015), deve proporcionar o desenvolvimento de habilidades e competências para o exercício do trabalho.

Com relação a code valorização/oportunidades, cinco mencionaram querer a valorização dentro da instituição. Compreendeu-se uma necessidade por parte dos servidores de se sentirem valorizados pela instituição e terem oportunidades de crescer profissionalmente.

Um dos servidores relatou que gostaria de que mais inovações acontecessem dentro da instituição. Neste quesito, percebeu-se o desejo de melhoria de oportunidades para as pessoas com deficiência com inovações que possam melhorar seu trabalho. Dentre estas inovações, pode-se mencionar o aumento da oportunidade de utilização de tecnologias assistivas.

A segunda unidade de contexto a ser observada é a unidade perspectivas externas, na 
qual constam as perspectivas fora da instituição. As unidades de registro encontradas foram as seguintes: aposentadoria e passar em outro concurso. Estas unidades de registro receberam o mesmo quantitativo de menções: quatro.

Quatro servidores com deficiência mencionaram querer passar em outro concurso, com nível superior. Isso mostra o desejo de ascensão, de melhoria de vida, de melhoria salarial, mas não apenas isso. Demonstra o intento de se obter qualidade de vida por estar fazendo o que se gosta. Bastos (1994) aponta que a Administração Pública Direta percorre um trajeto mais longo para atingir graus significativos de comprometimento organizacional. Atribui essa morosidade a estilos em gestão autoritários, ausência de política da gestão de pessoas fundamentada em mérito, como também a uma política salarial que não consegue reter pessoas com melhores qualificações. Quatro servidores falaram que já têm tempo ou estavam próximos da aposentadoria, no entanto, estes ainda tencionam se qualificar. Um servidor relatou insegurança ao realizar o seu trabalho, pois teve que enfrentar resistência de protestos estudantis.

\section{CONSIDERAÇÕES FINAIS}

Este artigo teve por objetivo analisar as percepções de pessoas com deficiência sobre o processo de socialização organizacional em uma Instituição Federal de Ensino Superior, tendo, para tanto procurado privilegiar as dimensões: engajamento à instituição, integração às pessoas, domínio profissional e perspectivas futuras.

No que diz respeito a primeira dimensão, engajamento à instituição, foi possível perceber, por meio da fala dos entrevistados, que, por problemas como a acessibilidade, por exemplo, há dificuldades para o engajamento institucional. A instituição deve rever sua infraestrutura para que sejam dadas condições de acessibilidade a todas as pessoas, sejam elas servidores, alunos ou público externo que possuam algum tipo de limitação. Isso significa que deve haver a instalação de pisos táteis e de pontos fixos para apoio aos deficientes visuais, adequação das rampas e nivelamento das calçadas para facilitar a locomoção de cadeirantes, manutenção dos elevadores e colocação de rampas de acesso nos prédios da instituição. Outro fator mencionado que dificulta o engajamento institucional foi a falta de conhecimento da história e objetivos da instituição, o que pode ser sanado por meio de seminários, palestras, apresentação de vídeos etc. Verificou-se que a maneira de ingresso não influencia diretamente no engajamento, mas que os servidores sentem necessidade de um Seminário de Ambientação específico para os trabalhadores com deficiência e de um programa de acompanhamento de profissionais com deficiência. Servidores surdos mencionaram o desconhecimento de libras por parte dos colegas e o despreparo dos funcionários em atender as pessoas com diferença funcional.

Na segunda dimensão, integração às pessoas, apesar de os servidores, em geral, terem enfatizado ter boas relações com colegas de trabalho, chefias e subordinados, destacaram-se as dificuldades que os servidores surdos enfrentam quando se relacionam com colegas ou mesmo quando estão atendendo o público, tais como: pessoas que viram as costas e saem falando, outros chamam o servidor surdo de outra sala, lotam o servidor em locais onde o fluxo de pessoas e a demanda são intensos. Também constatou-se que o acesso à informação é um problema para que ocorra a inclusão das pessoas dentro do ambiente organizacional.

Ao buscar compreender a terceira dimensão, domínio profissional, prevaleceu na fala dos entrevistados a noção de que os servidores com deficiência, na maioria das vezes, têm que mostrar um nível de competência maior do que outras pessoas para provar que são capazes. E este ponto está muito relacionado com as situações de trabalho, porque, se não forem dadas condições desses profissionais trabalharem, eles não têm como desenvolver todo seu 
potencial.

Finalmente, na dimensão perspectivas futuras, pode-se perceber que os servidores com deficiência querem continuar se qualificando, têm perspectivas de conseguir passar em outros concursos ou mesmo em um concurso dentro da própria instituição, num cargo mais elevado. Em virtude do engessamento da carreira, são somente estas as modalidades de melhoria: a qualificação ou um concurso em outra área ou outra instituição.

Em todo o artigo, a unidade de registro em que mais houve falas foi a acessibilidade, com um total de 55 citações. Neste ensaio, entretanto, o objetivo não foi somente se reportar à acessibilidade. Muito pelo contrário, assentou-se em saber como ocorreu a assimilação de valores da organização, como estava ocorrendo o acesso a informações, as condições materiais de trabalho, saber se os servidores conheciam a história, os valores e os objetivos da instituição, se eles compreendiam as relações de poder e sabiam a quem se dirigir caso precisassem de algo. Buscou-se descobrir também o meio de ingresso na instituição, como aconteceu a ambientação, lotação etc; saber se os servidores tinham acesso fácil às informações, se eles se sentiam participando das decisões institucionais, dificuldades encontradas em relação à acessibilidade; se eles se sentiam integrados, se trabalhavam em conjunto e se consideravam aceitos pelo grupo de trabalho. Foram analisadas relações com a chefia, colegas e subordinados, se no grupo de trabalho havia relações de confiança e se os servidores se reuniam com os colegas fora da instituição. Também se verificaram aspectos ligados a inclusão, conhecimento mútuo, impacto com relação ao uso de terminologias para se referir à pessoa com deficiência e se eles haviam passado por situações de discriminação dentro da instituição; se eles se viam como profissionais competentes e se sua competência era reconhecida por superiores e colegas de trabalho; se achavam que davam o melhor de si para a instituição, se tinham familiaridade com as siglas e os termos usados na instituição e se a instituição oferecia cursos de qualificação; se eles tinham interesse em se qualificar ou se tinham dificuldades para serem liberados para os cursos. Outro ponto enfatizado pela pesquisa foi saber se os servidores com deficiência se sentiam valorizados e que expectativas eles tinham dentro da instituição. Enfim, buscou-se entender como ocorreu a socialização destes servidores, tomando como base todos esses aspectos. Esta é a razão do título: Além da acessibilidade: desafios da socialização organizacional de pessoas com deficiência em uma Instituição Federal de Ensino Superior.

O estudo também teve limitações, como dificuldade de acesso aos dados pessoais para contato com os servidores com deficiência da IFES. Inicialmente, conseguiu-se apenas a relação com os setores onde os servidores trabalhavam. Alguns servidores também se recusaram a participar do estudo, ou marcavam e, na hora da entrevista, cancelavam.

$\mathrm{O}$ artigo realizado contribui tanto para que as organizações e a sociedade possam ter uma melhor compreensão de como acontece o processo de socialização desses profissionais, quanto dos fatores ainda limitantes e dos possíveis avanços que ainda devem ser buscados. Contribui, ainda, para que sejam repensadas as adaptações a serem realizadas para a inclusão de servidores, alunos e público externo com deficiência. A realização de pesquisas em organizações privadas torna-se interessante no sentido de compará-las com os resultados obtidos nesta investigação relativa a uma universidade pública.

\section{REFERÊNCIAS}

ANDRADE et al. Táticas organizacionais; desenvolvimentista; conteúdos e informação; tendências integradoras: a socialização organizacional abordada sob quatro correntes distintas.

Revista da Universidade Vale do Rio Verde, v. 10, n. 2, p 239-250, 2012. 
ARAÚJO, J. P.; SCHMIDT, A. A inclusão de pessoas com necessidades especiais no trabalho: a visão de empresas e de instituições educacionais especiais na cidade de Curitiba. Revista Brasileira de Educação Especial, v. 12, n. 2, p 241-254, 2006.

BARDIN, L. Análise de conteúdo. São Paulo: Edições 70, 2011.

BASTOS, A. V. B. Comprometimento organizacional: seus antecedentes em distintos setores da administração e grupos ocupacionais. Temas em Psicologia, v. 2, n. 1, p 73-90, 1994.

BERGER, P. L.; LUCKMANN, T. Construção social da realidade. Tradução: Floriano de Souza Fernandes. 35 ed. Petrópolis: Vozes, 2013.

BORGES et al. Re-construção e validação de um inventário de socialização organizacional.

Revista de Administração Mackenzie, v. 11, n. 4, 2010.

BORGES, L. O.; ROS-GARCIA, M.; TAMAYO, A. Socialización organizacionnal: tácticas y autopercepción. Revista de Psicología del Trabajo y de las Organizaciones, v. 17, n. 2, p 173-196, 2001.

BORGES et al. Sociologia Organizacional. In: SIQUEIRA, M. M. M. Novas medidas do comportamento organizacional: Ferramentas de diagnóstico e de Gestão. Porto Alegre: Artmed Editora, 2014.

BORGES, L. O.; ALBUQUERQUE, F. J. B. Socialização organizacional. Psicologia, organizações e trabalho no Brasil. Porto Alegre: Artmed, p. 331-356, 2014.

BRASIL. Classificação Internacional de Funcionalidade, Incapacidade e Saúde. 2004.

BRASIL. Lei n. 8.213, de 24 de julho de 1991. (1991). Dispõe sobre os Planos de Benefícios da Previdência Social, e dá outras providências. Brasília, DF, 1991.

BRASIL. Ministério da Saúde, Secretaria de atenção à saúde. Departamento de ações programáticas estratégicas. Manual de legislação em saúde da pessoa com deficiência. 2006.

BRASIL. Convenção sobre os direitos da pessoa com deficiência (2007). Protocolo facultativo à Convenção sobre os direitos da pessoa com deficiência: Decreto legislativo $\mathrm{n}^{\circ}$ 186, de 9 de julho de 2008: Decreto $\mathrm{n}^{\circ}$ 6.949, de 25 de agosto de 2009. Brasília: Secretaria dos Direitos Humanos, 2011.

CARVALHO-FREITAS, M. N. Percepções sobre as possibilidades de trabalho de pessoas com deficiência. In: III Congresso Brasileiro de Psicologia Organizacional e do Trabalho. Anais... Florianópolis, SC, 2008.

CARVALHO-FREITAS et al. Socialização Organizacional de pessoas com deficiência. Revista de Administração de Empresas, v. 50, n. 3, p. 264, 2010.

CHAO et al. Organizational socialization: Its content and consequences. Journal of Applied psychology, v. 79, n. 5, p. 730, 1994.

DOUGHERTY, Deborah et al. Handbook of organization studies. London: Sage, 1996.

GENARI, D.; IBRAHIM, C. V. D.; IBRAHIM, G. F. A percepção dos servidores públicos sobre a socialização organizacional: um estudo no Instituto Federal de Educação, Ciência e Tecnologia do Rio Grande do Sul. HOLOS, v. 5, p. 313-328, 2017.

GODOY. A.S. Estudo de caso qualitativo. In: GODOI, C. K.; BANDEIRA-DE-MELO, R.; SILVA, A. B. (orgs.) Pesquisa qualitativa em estudos organizacionais: paradigmas, estratégias e métodos. 2. ed., São Paulo: Saraiva, 2010.

HAMMES, I. C.; NUERNBERG, A. H. A inclusão de pessoas com deficiência no contexto do trabalho em Florianópolis: relato de experiência no sistema nacional de emprego. Psicologia Ciência e Profissão, v. 35, n. 3, 2015.

HOFFMANN, C.; TRAVERSO, L. D; ZANINI, R. R. Contexto de trabalho das pessoas com deficiência no serviço público federal: contribuições do inventário sobre trabalho e riscos de adoecimento. Gestão e Produção, São Carlos, v. 21, n. 4, 2014.

IBGE (INSTITUTO BRASILEIRO DE GEOGRAFIA E ESTATÍSTICA). Censo Demográfico 2010. BRASIL: IBGE, 2011. 
LEITÃO, V. M. Caminhos para a acessibilidade na UFC. In: LEITÃO, V. M.; VIANA, T. V. Acessibilidade na UFC: tessituras possíveis. Fortaleza: Edições UFC, 2014.

LEVY JUNIOR, M. Socialização. In: CARDOSO, F.H.; IANNI, O. (Org.) Homem e sociedade: leituras básicas de Sociologia geral. 12 ed. São Paulo: Editora Nacional, 1980.

LIMA, L. B.; JURDI, A. P. S. Empregabilidade de pessoas com deficiência no Município de Santos/SP: mapeamento de políticas públicas e práticas institucionais. Revista Brasileira de Educação Especial, v.20, n.4, p.513-524, 2014.

MANFREDI, S. M. Trabalho, qualificação e competência profissional: das dimensões conceituais e políticas. Educação e Sociedade, v. 19, n. 64, p. 13-49, 1998.

MOREIRA, L. B.; CAPPELlE, M. C. A.; CARVALHO-FREITAS, M. N. A dinâmica identitária de pessoas com deficiência: um estudo no brasil e nos estados unidos. Revista de Administração Mackenzie, v. 16, n. 1, p. 40, 2015.

MOREIRA, Lílian Barros et al. Socialização organizacional de pessoas com deficiência: um estudo no Brasil e nos Estados Unidos. João Pessoa, GPR, 2011.

OLIVEIRA et al. A socialização organizacional dos servidores da UFRN, segundo grupo ocupacional e tempo de serviço. Revista Psicologia: Organizações e Trabalho, v. 8, n. 1, p. 118-141, 2008.

PERLIN et al. Inclusão de Pessoas com Deficiência no Mercado de Trabalho: Um Estudo numa Empresa do Setor Cerâmico. Desenvolvimento em Questão, v. 14, n. 34, p. 214-236, 2016.

PHILERENO et al. Qualificação das pessoas com deficiência para o mercado de trabalho: um estudo de caso em Caxias do Sul-RS. Revista Estudo \& Debate, v. 22, n. 1, 2015.

SANTOS et al. Influência da socialização organizacional sobre o comprometimento organizacional: um estudo de caso na Polícia Militar de Sergipe. I CONGRESSO INTERNACIONAL DE DESEMPENHO DO SETOR PÚBLICO. Anais... Santa Catarina, 2017.

SANTOS et al. Políticas de Inclusão de pessoas com deficiência no mercado de trabalho: uma análise sobre o caso de Lavras (MG). Revista Foco, v. 8, n. 2, p.04-15, 2016.

SASSAKI, Romeu Kazumi. Inclusão: construindo uma sociedade para todos. 8. ed. Rio de Janeiro: WVA, 2010.

SCHEIN, E. H. Organizational socialization and the Profession of Management. Industrial Management Review, v. 9, n. 2, p. 1-14, 1988.

SILVA, P.; PRAIS, F. G.; SILVEIRA, A. M. Inclusão da pessoa com deficiência no mercado de trabalho em Belo Horizonte, Brasil: cenário e perspectiva. Ciência \& Saúde Coletiva, v. 20, n. 8, p. 2549-2558, 2015.

TAORMINA, R. J. Organizational socialization: A multidomain, continuous process model. International Journal of Selection and Assessment, v. 5, n. 1, p. 29-47, 1997.

VAN MAANEN, J. Processando as pessoas: estratégias de socialização organizacional. In: FLEURY, M T. L.; FISCHER, R. M. Cultura e poder nas organizações. 2. ed., São Paulo: Atlas, 2007. 